\title{
CAMINHOS E PERCALÇOS DA EDUCAÇÃO INFANTIL NO BRASIL
}

Fernanda Soares Godoi Yano do Canto, Valéria Anésia Brumatti Jacon, Carmen Lúcia Dias

Universidade do Oeste Paulista - UNOESTE, Mestrado em Educação, Presidente Prudente, SP. E-mail: godoyfefe@gmail.com

\section{RESUMO}

Este artigo tem por objetivo apresentar reflexões que envolvem a Educação Infantil, tomando como ponto de análise e fundamentação teórica a legislação e a prática pedagógica corrente. Foi utilizada como metodologia a pesquisa documental, por meio de ensaio bibliográfico, onde abordamos alguns aspectos mais relevantes de que trata a Constituição Brasileira de 1998 e a Lei de Diretrizes e Bases LDB 9394/96, dentre outras, acerca da formação dos profissionais da educação infantil. E com a contribuição desses documentos, pode-se observar que a discussão desses temas ocorre tendo em vista os objetivos e finalidades dessa etapa da educação.

Palavras-chave: educação infantil, infância, história, legislação, formação docente.

\section{PATHWAYS AND PITFALLS OF EARLY CHILDHOOD EDUCATION IN BRAZIL}

\section{ABSTRACT}

This article has aimed to present reflections that involve the kindergarten education taking as a main point for analysis and theorical foundation the current legislation and pedagogical pratice. It was used as methodology the documentary research, through bibliographic essay, amongst the most relevant aspects that are approached are, the Brazilian Constitution of 1998 and the Lei de Diretrizes e Bases LDB 9394/96, which talk about the formation of the professionals of the kindergarten education. Considering the contribution of these documents, it is possible to observe that the discussion of these particular points happen focusing on the aims and purposes of this school level.

Keywords: Child Education. Infancy. History. Legislation. Teacher Education. 


\section{INTRODUÇÃO}

A educação infantil tem sido tratada com descaso pelo poder público e vista pela sociedade como uma fase na qual a criança vai para a escola apenas para usufruir de uma assistência social (em creches) e para brincar ou para ser preparada para o ingresso no Ensino Fundamental (na préescola).

Dessa maneira é de fundamental relevância que o professor da Educação Infantil tenha uma formação que o coloque em contato com outras áreas do conhecimento que estudam e conhecem a criança. Tais conhecimentos favorecerão o desenvolvimento de suas atividades com as crianças pequenas reconhecendo suas necessidades desde bebês, auxiliando-o na organização e planejamento de ambientes promotores de desenvolvimento, socialização e aprendizagem das crianças de zero a cinco anos.

Esse artigo tem por objetivo abordar um pouco da história da Educação Infantil brasileira e a dificuldade encontrada pela maioria dos professores de Educação Infantil em desempenhar um trabalho de qualidade com as crianças pequenas devido à escassez de políticas públicas direcionadas à formação desses profissionais, bem como sua desvalorização enquanto profissional da educação.

Para isso, foi utilizada como metodologia a pesquisa documental, por meio de ensaio bibliográfico, realizando assim, várias leituras acerca da temática sobre formação de professores para a Educação Infantil no Brasil, tomando como referência a Constituição Brasileira de 1998, a Lei de Diretrizes e Bases da Educação Nacional, o Referencial Curricular Nacional para a Educação Infantil, entre outros.

Espera-se que a temática aqui refletida ao ser socializada possa contribuir para uma reflexão acerca da melhoria na qualidade da Educação Infantil através da conscientização sobre a importância de se investir em políticas públicas de formação e valorização dos profissionais que atuam nessa área.

\section{DISCUSSÃO}

A Educação Infantil começou a existir para atender aos que não tinham assistência de suas famílias. Kramer (1984) conta que, do descobrimento até 1874, existiu a "roda dos desvalidos", para cuidar das crianças abandonadas. De 1874 até 1899, alguns médicos, juntamente com outras pessoas interessadas, tentaram prestar algum atendimento às outras crianças, que, embora tivessem família, não tinham munidas suas necessidades, todavia esses projetos não tiveram 
prosseguimento. Os atendimentos mais proveitosos surgiram a partir de 1900, especialmente quanto aos aspectos médicos e escolares.

Desta forma, a Educação Infantil começou a ter vida própria na rede pública somente a partir de 1930. Até a década de vinte, o atendimento à criança era oferecido basicamente por instituições particulares e primordialmente às crianças ditas carentes. Com a implantação da industrialização no país e com o advento da imigração, a questão do atendimento infantil foi intensificada pelos operários em favor de seus filhos. Os donos das indústrias antecederam esta reivindicação, construindo creches e escolas próximas às indústrias e, com isso, esperava-se que as mães, satisfeitas, produzissem melhor. As outras creches, fora dos arredores das indústrias, eram mantidas por entidades filantrópicas, com a ajuda de pessoas ricas e do governo. Essa era uma visão de trabalho de cunho assistencialista, o foco da preocupação ocorria sobre alimentação, higiene e segurança física das crianças.

Getúlio Vargas criou a Consolidação das Leis Trabalhistas (CLT) em 1942, determinando a organização de berçários pelas empresas para abrigar os filhos das operárias durante o período de amamentação.

A partir de 1950, com o avanço da industrialização e com o aumento do número de mulheres de classe média entrando no mercado de trabalho, intensificou-se a demanda por creches. O contexto econômico e político nas décadas de 70 e 80, com movimentos operários e feministas, propiciou um movimento vibrante na luta pela democratização da educação pública brasileira, possibilitando a conquista, na Constituição de 1988 , do reconhecimento da educação em creches e pré-escolas como um direito da criança e um dever do Estado.

As tendências educacionais vigentes foram exercendo influência sobre o processo e a Educação Infantil passou pelas fases compensatória, assistencialista e preparatória à escola, até chegar ao modelo atual, que propõe condições ao desenvolvimento integral da criança.

A abordagem compensatória parte da ideia de que a criança deve ser vista no interior de uma sociedade de classes e não como ela mesma. A Educação Infantil era uma forma de resolver a miséria, a pobreza e os problemas familiares. $O$ assistencialismo era justificado com a necessidade imediata que algumas crianças tinham de alimentação, cuidados médicos e lugar para permanecerem enquanto sua família trabalhava. A ideia de que a criança deveria chegar ao ensino formal com conhecimentos prévios levou ao caráter preparatório da pré-escola. Os mais recentes estudos e pesquisas em educação mostram que a criança deve ser acompanhada, enquanto criança, em seu desenvolvimento integral. 
Especialmente a partir da década de 70, quando se verifica uma rápida expansão da rede de creches, inúmeras críticas foram feitas às instâncias governamentais, denunciando o caráter discriminador da manutenção de diferentes redes de socialização para as crianças menores de sete anos, quer por iniciativas de atendimento de baixíssima qualidade, quer pela falta de qualificação dos recursos humanos ou da proposta institucional.

No entanto, houve sempre um discurso justificador para essas práticas. Seria o caráter de urgência nas soluções para os problemas da infância que acabaria por impor iniciativas de caráter predominantemente assistencial. E se este pouco se constituía em programas marcados por um caráter paternalista, moralizador, discriminador, de qualidade questionável, era porque,

[...] via de regra a política de atendimento á criança pequena vinha sendo utilizada com um sentido nitidamente desmobilizador de que o discurso avançado se serve para dissimular a manutenção de práticas retrógradas, obtendo favores e votos com custo relativamente baixo e, com isto, ajudando a manter o atávico desinteresse que certas camadas dirigentes nutrem pelos problemas da maioria da população. (GARCIA, 1993, p. 139).

A partir da consciência de seus direitos e da participação em movimentos sociais, a população brasileira teve papel central numa das maiores conquistas da educação infantil no Brasil, o reconhecimento, na Constituição de 1988 - Inciso IV do art. 208 -, do direito à educação de todas as crianças de 0 a 6 anos e do dever do Estado de oferecer creches e pré-escolas para tornar fato esse direito. Movimentos sociais e instâncias públicas, municipais e estaduais vêm se esforçando para expandir com qualidade a educação infantil e enfrentar os desafios que se colocam. Pela primeira vez na história da educação brasileira, em 1994 foi formulada uma Política Nacional de Educação Infantil (MEC) com diretrizes para a formação dos profissionais.

Em 20 de dezembro de 1996, foi sancionada a Lei de Diretrizes e Bases da Educação Nacional (LDB 9394/96). É uma lei flexível e descentralizadora, que fortalece os sistemas estaduais de educação e que garante a universalização da educação infantil, significando que todas as crianças de 0 a 6 anos deverão ser assistidas.

A educação infantil é a primeira etapa da educação básica. Tem como finalidade o desenvolvimento integral da criança até 6 anos de idade, em seus aspectos físico, psicológico, intelectual e social, complementando a ação da família e da comunidade (BRASIL, 1996, p.1).

Em 1982, por uma decisão do Ministério da Educação, a educação pré-escolar (4 a 6 anos) pode ser incluída na educação básica, mas a garantia de que isso efetivamente acontecesse veio com a nova LDB (Seção II, art. 30), além do atendimento também de 0 a 3 anos. Isso foi 
importante porque, embora os especialistas e as autoridades soubessem da importância dos primeiros anos de vida para o desenvolvimento do indivíduo, pouca coisa era realizada, especialmente no âmbito oficial.

Assim, a partir de 1996, a educação infantil é reconhecida no país como direito da criança e dever do Estado, sendo subdividida em duas faixas de idade: de 0 a 3 anos (creches) e de 4 a 6 (pré-escolas).

Hoje, diversas instituições referem-se à creche ou pré-escola usando um ou outro critério, de modo que esta é uma denominação ainda pouco invariável para os que atuam na área e para a população em geral. Apesar da coexistência dos nomes, entendemos como creche o espaço para a criança de 0 a 3 anos e a pré-escola para as crianças de 4 a 5 anos, funcionando em meio período ou horário integral. A responsabilidade sobre as duas modalidades é ou deveria ser assumida pela instância educacional pública.

A educação infantil passou a ser à base do sistema de ensino, aliviando a 1ạ série do ensino fundamental, ficou determinado que a Educação Infantil faz parte da educação básica, que abrange também o ensino fundamental e o ensino médio.

O atendimento pedagógico deverá ser realizado por professores com formação específica, sendo possível, em sua organização pedagógica, flexibilidade quanto à seriação, admitindo-se avanços de acordo com o ritmo de cada criança.

Assim, a formação do professor requer que se observe e se dê atenção aos cursos responsáveis por essa tarefa. Atualmente, a responsabilidade pela formação desses profissionais em nível superior é dos cursos de licenciatura. Conforme art. 62 da LDB, Lei no 9.394/96,

[...] a formação de docentes para atuar na educação básica far-se-á em nível superior, em curso de licenciatura, de graduação plena, em universidades e institutos superiores de educação, admitida, como formação mínima para o exercício do magistério na educação infantil e nas quatro primeiras séries do ensino fundamental, a oferecida em nível médio, na modalidade Normal. (BRASIL, 1996, art. 62).

Para que as especificidades desse período sejam respeitadas, é necessário que as instituições "cumpram duas funções complementares e indissociáveis: cuidar e educar, complementando os cuidados e a educação realizados na família ou no círculo da família". (BRASIL, 1994, p. 17).

Nesse sentido, em 1998, o MEC elaborou e distribuiu às Redes Públicas de Ensino e aos professores da Educação Infantil, o Referencial Curricular Nacional para Educação Infantil (RCNEI), documento composto de três volumes, com a função de subsidiar as políticas públicas de 
educação infantil, com vistas à melhoria da qualidade e equalização do atendimento a educação infantil. Contudo, nossa realidade se mostrou ainda distante ao atendimento dessa nova proposta para o cotidiano escolar infantil por apresentar um quadro de educadores pouco qualificados e não poder contar com a participação das famílias na dinâmica das instituições, pois estas se apresentam como acanhados pela instituição, recebendo como favor e não como direito da criança.

Descrevendo o processo de elaboração do RCNEI (1998) e, antes de chegar à versão final, Ferri $(2008$, p. 46) coloca que "[...] o texto preliminar do RCNEI foi enviado a 700 pareceristas: profissionais de educação infantil, administradores e pesquisadores. Destes, 230 responderam ao MEC".

Considerando o número de pessoas envolvidas, pode-se concluir que o RCNEI (1998) é resultado de um trabalho efetivado em conjunto por professores e diversos profissionais empenhados em contribuir para o desenvolvimento da Educação Infantil no Brasil.

Outro fator apontado no RCNEI (1998) é a referência a um modelo de infância, remetendo a uma leitura de criança idealizada. Isso nos diferencia da maioria das instituições existentes, e desconhecendo parte dos conhecimentos anteriormente sistematizados em publicações, teses, dissertações e pesquisas divulgadas, pois a realidade das instituições escolares é a falta de preparo docente e deficiência de materiais.

Quanto ao preparo docente, o RCNEI (1998) pressupõe um educador qualificado, capaz não só de analisar tipos de brincadeiras e efetivá-las, considerando o potencial da atividade e da criança, como também de prosseguir com a estimulação, após cada resposta individual. Mais uma vez, a realidade se mostra distante da proposta. Portanto, o RCNEI (1998),

Aponta metas de qualidade que contribuem para que as crianças tenham um desenvolvimento integral de suas identidades, capazes de crescerem como cidadãos cujos direitos à infância são reconhecidos. (BRASIL, 1998, p. 7).

Um dos atuais desafios da Educação Infantil é reconhecer e compreender o modo particular como as crianças são e estão no mundo. Nesse sentido, deve-se ressaltar o importante papel dos profissionais que atuam na área em relação ao desenvolvimento psicopedagógico da criança. Então,

Embora os conhecimentos derivados da psicologia, antropologia, sociologia, medicina, etc. possam ser de grande valia para desvelar o universo infantil apontando algumas características comuns de ser das crianças, elas permanecem únicas em sua individualidade e diferença. (BRASIL, 1998, p. 22). 
O conhecimento a respeito da importância das experiências da primeira infância, por parte dos educadores, é vital para a elaboração de políticas e programas que visem promover e ampliar as condições necessárias para o exercício da cidadania das crianças.

No entanto, o RCNEI (1998) aponta caminhos e possibilidades para o professor, quando acredita nas capacidades das crianças com as quais trabalha, ressaltando a importância em criar situações educativas para que, dentro dos limites impostos pela vivência em coletividade, cada criança possa ter respeitados os seus hábitos, ritmos e preferências individuais. Nesse contexto, o professor é merecedor de atenção e incentivado para buscar inovações pedagógicas e seu aperfeiçoamento profissional.

Outras mudanças na legislação foram sendo introduzidas, entre elas a que define a redução da idade mínima obrigatória para o ingresso das crianças na Educação Básica, que passa a ser aos quatro anos e não mais aos seis, medida que deverá ser implementada progressivamente até 2016. A determinação está na Lei no 12.796 que, sancionada pela presidente Dilma Rousseff, ajusta a LDB à Emenda Constitucional (EC) 59/2009 (BRASIL, 2013).

As Diretrizes Curriculares Nacionais para a Educação Infantil (DCNEI), para as crianças de zero a três anos e nas chamadas pré-escolas para as de quatro a cinco anos, contemplam o trabalho nas creches, além de nortear as propostas curriculares e os projetos pedagógicos. Dessa forma, a Educação Infantil propicia um dos espaços de inserção da criança nas relações éticas e morais que permeiam a sociedade em que estão inseridas (BRASIL, 1998).

A criança deixa de ser vista como 'um adulto em potencial', passando a ser considerada como um sujeito que se constrói em interação com a vida social da qual faz parte. Dessa forma, o trabalho ganha sentido, as mudanças vão se processando e o novo sendo criado. Não é somente a criança que aprende, mas também o professor aprende e se atualiza com a criança.

Cabe ressaltar que, valorizar o saber docente é fundamental para alcançar um processo de ensino e aprendizagem de qualidade, pois as práticas dos professores estão intimamente relacionadas com suas experiências em sala de aula. Abdala (2006) ressalta que a construção da identidade do professor se dá pela necessidade e perspectivas que assumem em relação à sua formação e desenvolvimento profissional e pela importância que colocam na escola enquanto contexto de produção docente.

\section{CONCLUSÃO}

No decorrer da realização desse artigo pode-se perceber o quanto a infância brasileira tem sido negligenciada no transcorrer de sua história. Tratada com indiferença, ignorada não só pelo 
Estado, mas também pela sua própria família que na maioria das vezes Ihes ofereciam apenas os cuidados necessários à sobrevivência. O fato de a Educação Infantil ter sido desde seu início marcado pela segregação social e racial tem contribuído muito para que ela continue sendo, ainda hoje, uma educação dualista, na qual a maioria das crianças vindas das camadas populares continua excluída do direito a uma educação infantil de qualidade.

É interessante observar que nas últimas décadas, Leis e documentos importantes foram criados visando assegurar o direito das crianças de zero a cinco anos à educação infantil. Todavia, esses documentos não determinam a obrigatoriedade do governo de ofertar escolas gratuitas a todas essas crianças, nem apresentam programas de formação específica para os professores das creches e pré-escolas.

Nesse sentido, é necessário que a Educação Infantil e a formação de seus profissionais sejam reconhecidas de fato como prioridade das políticas de educação nacional. Apesar de conquistas importantes terem sido alcançadas no campo da educação infantil, ainda há um longo caminho a ser percorrido na busca de uma política educacional verdadeiramente comprometida com a formação, qualificação e valorização dos profissionais que atuam nesta área.

\section{REFERÊNCIAS}

BRASIL. Conselho Nacional de Educação. Diário Oficial da União, Brasília. 2006, Seção 1, p. 11. Disponível em: <http://portal.mec.gov.br/cne/arquivos/pdf/rcp01 06.pdf>. Acesso em: 18 out. 2014.

\section{. Constituição da República Federativa do Brasil, 1988.}

. Ministério da Educação e do Desporto, Secretaria de Educação Fundamental Referencial Curricular Nacional para a Educação Infantil. Brasília: MEC/SEF, 1998.

. Ministério da Educação. Conselho Nacional de Educação Conselho Pleno Resolução CNE/CP № 5, de 17 de Dezembro de 2009. Disponível em: <www.portal.mec.gov.br/documents/resolucao cne ceb002 2009>. Acesso em: 15 jul. 2014.

. Ministério da Educação. Dúvidas mais frequentes sobre educação infantil. 2013. Disponível em: <www.portal.mec.gov.br/index.php?option=com docman\&task. $>$. Acesso em: 10 mar 2013.

. Ministério da Educação. Lei de Diretrizes e Bases da Educação Nacional: Lei no 9.394, de 20 de dezembro de 1996, dispositivos constitucionais, emenda constitucional no 11 de 1996, Brasília: Senado Federal, 2004.

. Presidência da República. Casa Civil. Subchefia para Assuntos Jurídicos Lei no 11.796, de 29 de outubro de 2008. Disponível em: <www.planalto.gov.br/ccivil 03/ Ato20072010/2008/Lei/L11796.htm>. Acesso em: 16 abr. 2014. 
. Presidência da República. Casa Civil. Subchefia para Assuntos Jurídicos Lei no 12.796, de 4 de abril de 2013. Disponível em: <http://www.planalto.gov.br/CCIVIL 03/ Ato20112014/2013/Lei/L12796.htm>. Acesso em: 16 abr. 2013.

GARCIA, R. L. Revisitando a pré-escola. São Paulo: Cortez, 1993.

GUIMARÃES, C. M. Perspectiva para educação infantil. Araraquara: Junqueira \& Marin, 2005.

HADDAD, L. A creche em busca de identidade. Perspectivas e conflitos na construção de um projeto educativo. São Paulo: Loyola, 1991.

KRAMER, S. A política do pré-escolar no Brasil: a arte do disfarçar. 2. Ed. Rio de Janeiro: Achiamé, 1984.

KUHLMANN JR., M. Instituições pré-escolares assistencialistas no Brasil (1899-1922). Cadernos de Pesquisa, São Paulo, v. 78, p. 17-26, 1991.

LUZURIAGA, L. História da educação e da pedagogia. 7. ed. São Paulo: Editora Nacional, 1975.

ROSEMBERG, F \& CAMPOS, M. M. Creches e pré-escolas no hemisfério norte. São Paulo: Cortez: Fundação Carlos Chagas, 1994. 